\title{
Tratamiento quirúrgico del linfedema de miembro superior postratamiento del cáncer de mama
}

\author{
Surgical treatment of lymphedema of the upper limb \\ after breast cancer
}

Joaquín Pefaure ${ }^{1}$ Daniela Belén Rocca², Micaela Taverna ${ }^{3}$, Guillermo Artero ${ }^{4}$, Marcelo Mackfarlane ${ }^{5}$

\section{RESUMEN}

Introducción. El linfedema de miembro superior postratamiento del cáncer de mama es una afección progresiva y crónica que compromete a una gran cantidad de pacientes causando efectos físicos, psicológicos y sociales. El linfedema secundario se da en un 20-40\% de los casos luego de la cirugía del cáncer de mama con vaciamiento y radioterapia. Este es un problema desafiante. El tratamiento conservador ha demostrado no ser suficientemente exitoso por lo que su tratamiento quirúrgico es una buena opción. La transferencia microquirúrgica de nódulo linfático vascularizado (TNLV) brindó una nueva esperanza para este grupo de pacientes.

Material y métodos. En el periodo comprendido entre marzo 2016 y agosto 2018 se analizaron 16 pacientes con una edad promedio de 50,25. Se realizó tratamiento quirúrgico basándose en la transferencia de nódulo linfático vascularizado (TNLV) de la ingle a la axila por medio de una anastomosis microquirúrgica de la arteria circunfleja ilíaca superficial en pacientes que presentaron linfedema secundario al tratamiento del cáncer de mama. Se realizó simultáneamente a la cirugía reconstructiva de la mama con colgajo libre DIEP y también en un segundo tiempo quirúrgico. Tiempo quirúrgico de 4,3 horas y una estadía en internación

de 2,3 días.
Resultados. La vitalidad de los colgajos fue $100 \%$. Como morbilidad, se presentaron cuatro casos de seroma, una infección y una dehiscencia en la zona dadora. Con un seguimiento promedio de 10,43 meses y una reducción significativa de volumen del miembro afectado del $27.47 \%$ en comparación con el preoperatorio. La incidencia de celulitis descendió. La linfografía posoperatoria indicó una mejoría en el drenaje linfático del miembro afectado.

Conclusiones. La transferencia linfática vascularizada al miembro afectado en conjunto con la cirugía reconstructiva mamaria DIEP es un procedimiento seguro y eficaz en el tratamiento del linfedema de miembro superior en pacientes mastectomizadas con vaciamiento ganglionar y radioterapia.

Palabras claves: linfedema de miembro superior, cáncer de mama, transferencia microquirúrgica, nódulo linfático vascularizado.

\begin{abstract}
Purpose: Upper limb lymphedema post breast cancer treatment is a progressive and chronic condition that involves a large number of patients causing psychological, physical and social effects. The incidence of secondary lymphedema is about $20-40 \%$ before breast cancer treatment. This is a challenging problem. The conservative treatment has shown not to be successful enough so the surgery is a really good option. The vascularized lymph node transfer (VLNT) offers some hope to this group of patients. The purpose of the investigation is to demonstrate that te VLNT is an efficacious approach to treating postmastectomy upper limb lymphedema.

Methods: From March 2016 to August 2018 were analyzed sixteen patients with a mean age of 50.25 years. They all have secondary lymphedema. They underwent surgical treatment based on vascularized lymph node transfer from the groin to the axially area or elbow as a recipent site. The deep inferior epigastric perforator flap was made at the same time, as a stacked flap. In only six cases, the VLNT was made on a second surgical time. The serrato's vessels were used as a recipient vessels in the axilary area and a radial artery branch and the cephalic vein were used in the elbow.

Results: The flaps vitality was $100 \%$. There were four seroma cases, one infection and one dehiscence. At a mean follow up of 10.43 , the mean circumference reduction rate of the lymphedematous limb was about $27.47 \%$ between the preoperative and the postoperative groups. The postoperative lymphoscintigrapy showed a little improvement. The follow up of the vitality of the nodes was made by a lymphatic contrast tomography, and it showed all nodes survived. Conclusions: The vascularized lymph node transfer and the DIEP flap were confirmed as an effective and safe treatment to the secondary lymphedema in this type of patients, and it really improves postmastectomy upper limb lymphedema.
\end{abstract}

Key words: upper limb lymphedema, breast cancer, vascularized lymph node transfer.

\section{INTRODUCCIÓN}

El sistema linfático juega un rol importante en el mantenimiento de la homeostasis de los fluidos, en el sistema inmune y absorción en el tracto gastrointestinal. Existe una circulación linfática que consiste en una red de capilares linfáticos que se encuentran en la dermis que dre-

1. Jefe de División de Cirugía Plástica y Reparadora

2. Residente de Cirugía Plástica y Reparadora

3. Médica de Cirugía Plástica y Reparadora

4. Médico de planta. Especialista en Cirugía Plástica y Reparadora. Especialista en Cirugía Plástica y Reparadora. División Cirugía Plástica y Reparadora. Departamento de Cirugía. Hospital Donación Francisco Santojanni

$\square$ Correspondencia: revista@sacper.org.ar

Los autores no declaran conflictos de intereses

Recibido: 28/08/2019 / Aceptado: 30/08/2019 nan el exceso del fluido intersticial hacia los vasos linfáticos subcutáneos, luego hacia conductos linfáticos y terminan en ambas venas subclavias derecha e izquierda. La linfa es transportada dentro y fuera de los nódulos linfáticos por vía aferente y emergente de los conductos linfáticos. Se estima que existen entre 600-700 nódulos linfáticos en el cuerpo, con la mayor concentración en la axila, ingle, mediastino y tracto gastrointestinal. Una evidencia reciente ha demostrado conexiones linfaticovenosas que proveen drenaje alrededor de los tejidos hacia los nódulos linfáticos, así como retorno de los nódulos hacia la red venosa local. Cuando todo este proceso se altera se produce el linfedema. Estas disrupciones del sistema de transporte linfático llevan a la acumulación del fluido rico en proteínas en el espacio intersticial, presentándose distintos grados de linfedema.

Es una patología común que afecta a más de 250 millones de personas en el mundo. Podemos clasificarlo en linfede- 
TABLA 1. Pacientes con linfedema tratadas con transferencia de nódulo linfático vascularizado en el Hospital Santojanni, período $2016-2018$.

\begin{tabular}{|c|c|c|c|c|c|c|c|c|c|c|c|}
\hline Pacientes & Edad & Sitio & $\begin{array}{l}\text { Tratamien- } \\
\text { to del cán- } \\
\text { cer de mama }\end{array}$ & $\begin{array}{c}\text { Duración } \\
\text { de los sínto- } \\
\text { mas (meses) }\end{array}$ & \begin{tabular}{|c|} 
Circunferencia \\
miembro sano \\
preoperatorio $(\mathrm{Cm})$
\end{tabular} & $\begin{array}{c}\text { Circunferencia } \\
\text { miembro afe- } \\
\text { tado preope- } \\
\text { ratorio }(\mathrm{Cm})\end{array}$ & $\begin{array}{c}\text { Circunferen- } \\
\text { cia miembro } \\
\text { sano postope- } \\
\text { ratorio }(\mathrm{Cm})\end{array}$ & $\begin{array}{c}\text { Circunferencia } \\
\text { miembro afe- } \\
\text { tado postope- } \\
\text { ratorio }(\mathrm{Cm})\end{array}$ & $\begin{array}{l}\text { Tasa de reduc- } \\
\text { ción de la cir- } \\
\text { cunferencia } \\
\text { del miemrbo }\end{array}$ & $\begin{array}{c}\text { Complicaciones } \\
\text { POP }\end{array}$ & Seguimiento \\
\hline 1 & 49 & 1 & M-V-RT & 14 & 28 & 33 & 28,4 & 32,5 & $18,00 \%$ & & 12 \\
\hline 2 & 47 & D & M-V-RT & 8 & 19,5 & 23 & 20 & 22,5 & $28,57 \%$ & SER & 7 \\
\hline 3 & 34 & 1 & M-V-RT & 7 & 21,5 & 32 & 21 & 27 & $42,86 \%$ & & 15 \\
\hline 4 & 57 & 1 & M-V-RT & 12 & 31 & 42 & 31 & 41 & $9,09 \%$ & IZD & 3 \\
\hline 5 & 41 & D & M-V-RT & 4 & 28 & 38,5 & 27 & 36 & $14,29 \%$ & & 7 \\
\hline 6 & 69 & D & $M-V-R T$ & 21 & 25 & 30 & 25,5 & 28 & $50,00 \%$ & & 24 \\
\hline 7 & 51 & 1 & $M-V-R T$ & 12 & 28 & 32,5 & 28 & 31 & $33,33 \%$ & & 10 \\
\hline 8 & 40 & D & $M-V-R T$ & 84 & 26,5 & 40 & 27 & 37 & $25,93 \%$ & SER & 3 \\
\hline 9 & 65 & D & $M-V-R T$ & 30 & 25,5 & 36 & 25 & 34 & $14,29 \%$ & DZD & 8 \\
\hline 10 & 49 & $\mathrm{D}$ & M-V-RT & 60 & 22 & 35 & 22 & 34 & $7,69 \%$ & SER & 3 \\
\hline 11 & 52 & 1 & M-V-RT & 72 & 26 & 29 & 26,5 & 28 & $50,00 \%$ & & 10 \\
\hline 12 & 68 & $\mathrm{D}$ & $M-V-R T$ & 78 & 23 & 27 & 24 & 26,5 & $37,50 \%$ & & 8 \\
\hline 13 Caso $1^{*}$ & 36 & 1 & M-V-RT & 39 & 32,5 & 34 & 31,5 & 32,6 & $26,67 \%$ & & 27 \\
\hline 14 & 40 & D & M-V-RT & 5 & 25,5 & 29 & 26 & 28,5 & $28,57 \%$ & & 10 \\
\hline 15 Caso $^{* * *}$ & 47 & $\mathrm{D}$ & $M-V-R T$ & 12 & 21 & 23 & 21 & 22,15 & $25,00 \%$ & SER & 11 \\
\hline 16 & 59 & 1 & $M-V-R T$ & 5 & 31 & 40 & 32 & 38,5 & $27,78 \%$ & & 9 \\
\hline Promedio & 50,25 & & & 28,9375 & 25,96875 & 33,375 & 26,11875 & 31,6625 & 0,27472397 & & 10,4375 \\
\hline Rango & \begin{tabular}{|l}
$(34-69)$ \\
\end{tabular} & & & & & & & & & & $(3-27)$ \\
\hline
\end{tabular}

Todas las pacientes fueron tratadas con mastectomía + vaciamiento ganglionar + radioterapia. D: derecha. I: Izquierda. M: mastectomía. V: vaciamiento ganglionar. RT: radioterapia. SER: seroma en zona dadora. ZD: infección en zona dadora. DZD: dehiscencia en zona dadora. Estas pruebas fueron aplicadas para un análisis estadistico, con motivo de determinar la significancia de la circunferencia en el miembro afectado y el sano (por separado) en el preoperatorio y posoperatorio. Se tomó arbitrariamente la circunferencia B (codo). La tasa de reducción de la circunferencia del miembro afectado se calculó de la siguiente forma: (a-b). Deratoria. *: la paciente 13 es presentada en el caso clínico 1. \#: la paciente 15 es presentada en el caso clínico 2.

ma primario y linfedema secundario. El linfedema primario se da como resultado de anomalías genéticas o de desarrollo. Está clasificado según el tiempo de inicio en: linfedema congénito, linfedema precoz y linfedema tardío. El linfedema congénito se presenta al nacimiento o dentro de los 2 primeros años de vida, el linfedema precoz típicamente se presenta dentro la pubertad hasta antes de los 35 años, y el linfedema tardío se presenta después de los 35 años.

El linfedema secundario es resultado de causas posnatales, como trauma, infección, malignidad o radiación del sistema linfático. La causa principal en el mundo de linfedema secundario es la filariasis, una parasitosis producida por el parásito Wuchereria bancrofti, afectando a países en vías de desarrollo. Otra causa importante de linfedema es la que se presenta como consecuencia de las terapias oncológicas, particularmente del cáncer de mama. En el tratamiento quirúrgico del cáncer de mama, la mastectomía, junto con la resección de nódulos linfáticos y radioterapia, son el precursor clásico de linfedema. También, se observa en pacientes bajo tratamiento por tumores sólidos en cualquier parte del cuerpo. De cualquier manera, cual sea la causa, la obstrucción o lesión del sistema linfático, resulta en una serie de eventos específicos que llevan al linfedema.

Afortunadamente no todas las pacientes con terapia por cáncer de mama desarrollan linfedema. Existen estudios que revelan que la incidencia es de $21 \%$, pero esta varía sustancialmente dependiendo de los criterios diagnósticos. Según Cheng ${ }^{18}$, la incidencia es del 10\% en pacientes que presentaron exéresis de ganglios linfáticos axilares y aumenta al $40 \%$ en aquellas que reciben radioterapia. El inicio es muy variable, desarrollándose linfedema dentro de los 8 meses posteriores a la cirugía, con un desarrollo de un $75 \%$ de signos de linfedema dentro de los primeros tres años. Esto tiene que ver con la influencia de los factores de riesgo en el desarrollo, inicio y progresión de la enfermedad, como ser: obesidad, radiación, infección y factores genéticos.
La progresión natural del linfedema proviene de la acumulación de líquido rico en proteínas en el espacio intersticial, manifestándose como un síntoma temprano de edema blando con prurito en la extremidad afectada. Este síntoma inicial se presenta como resultado de una inflamación de los tejidos y estimulación de la fibrosis por diferentes mecanismos. Con el tiempo, la pérdida de la función linfática resulta en la adipogénesis, con el consiguiente depósito de tejido adiposo en el tejido subcutáneo. Todo prosigue como un efecto de feedback positivo, empeorando los síntomas del linfedema, progresando a una voluminosa fibrosis grasa y edematosa extremidad, dolorosa, que debilita la actividad diaria de la paciente.

Existen dos tipos de tratamientos para el linfedema: conservador y quirúrgico. Las opciones quirúrgicas se dividen en procedimientos de resección y procedimientos fisiológicos. La idea de estos últimos es crear nuevos canales para incrementar la capacidad del sistema linfático de transportar la linfa. Varios procedimientos fueron desarrollados para drenar el exceso de fluido acumulado en las áreas linfaticoedematosas hacia otras bases linfáticas o la circulación venosa. Con el advenimiento de las técnicas microquirúrgicas se tienen nuevas opciones para el manejo del linfedema, la anastomosis linfaticovenosa (ALV) y la transferencia de nódulo linfático vascularizado (TNLV). Estas cirugías tienen el objetivo de restablecer la alteración que desencadena el linfedema a través de un bypass de las áreas de linfáticos dañados hacia el sistema venoso o mediante el reemplazo de los canales y nódulos linfáticos perdidos, respectivamente.

El propósito de este trabajo es evaluar si la transferencia de nódulo linfático vascularizado es efectiva en el tratamiento del linfedema producido en pacientes postratamiento del cáncer de mama: mastectomía, vaciamiento ganglionar y radioterapia. 


\section{PACIENTES Y MÉTODOS.}

Este estudio retosprospectivo fue realizado en el Hospital Donación Francisco Santojanni, Buenos Aires, Argentina. Abarca un período comprendido entre marzo de 2016 y agosto de 2018. Se analizaron dieciséis pacientes con edad promedio 50,87 (con un rango de edades de 36 a 69 años) con linfedema de miembro superior secundario a terapias asociadas al cáncer de mama, que fueron tratadas mediante terapia quirúrgica fisiológica, realizándose transferencia de nódulo linfático vascularizado (TNLV).

A todas se les realizó, como tratamiento del cáncer de mama, cirugía conservadora más radioterapia con posterior mastectomía total. Las dieciséis pacientes del protocolo presentaron linfedema grado II. Se les realizó una historia clínica detallada con interrogatorio y examen físico. Dentro del interrogatorio se incluyeron ítems importantes como: edad, sintomatología (pesadez del miembro, dolor, infecciones, parestesias), tiempo de evolución de la sintomatología, enfermedades de base y antecedentes (DBT, HTA, tabaquismo, drogas). Se interrogó acerca del cáncer de mama: tipo y estadio de enfermedad, tratamiento realizado (cirugía realizada, radioterapia, quimioterapia) y examen físico. Se realizó la medición de la circunferencia del miembro. Se tomaron las siguientes mediciones: 1) $15 \mathrm{~cm}$ proximal al epicóndilo del húmero; 2) el codo, específicamente el punto medio entre el epicóndilo medial y el epicóndilo lateral; 3) $10 \mathrm{~cm}$ distal al epicóndilo lateral; 4) la muñeca; 5) la articulación metacarpofalángica ${ }^{17}$ (Figura 1). Se realizan las mediciones en ambos brazos. Se realizó una linfografía preoperatoria en todas las pacientes para evaluar el sitio de restricción linfática. Se les realizó como tratamiento reconstructivo un colgajo libre microquirúrgico DIEP (deep inferior epigastric perforator) con la transferencia de nódulo linfático vascularizado desde la ingle a la axila en uno y dos tiempos quirúrgicos (Tabla $\mathbf{1}$ ).

\section{DIAGNÓSTICO}

Para un tratamiento adecuado del linfedema, es necesario conocer y entender el diagnóstico y el grado de la enfermedad.

Los principales síntomas incluyen: edema, pesadez, discapacidad, engrosamiento/endurecimiento de los tejidos, parestesias, infecciones recurrentes y dolor ocasional.

El diagnóstico diferencial del linfedema comprende: insuficiencia cardíaca congestiva, infección, malignidad primaria/recurrente, insuficiencia vascular, trombosis venosa aguda, insuficiencia renal, insuficiencia hepática, desequilibrio hidroelectrolítico, hipoproteinemia, neuropatía periférica.

Se realiza una historia clínica detallada, con una correcta anamnesis y un adecuado examen físico. Esto es
TABLA 2. Valores de referencia estándar para cada QAI.

\begin{tabular}{|l|c|c|c|}
\hline & $\begin{array}{c}\text { Patrón } \\
\text { normal }\end{array}$ & $\begin{array}{c}\text { Patrón de disminu- } \\
\text { ción funcional }\end{array}$ & $\begin{array}{c}\text { Patrón de } \\
\text { obstrucción }\end{array}$ \\
\hline Axila & $0,82 \pm 0,29$ & $0,42 \pm 0,41$ & $0,18 \pm 0,16$ \\
\hline Brazo & $1,15 \pm 0,10$ & $0,79 \pm 0,30$ & $3,12 \pm 3,07$ \\
\hline Antebrazo & & & \\
\hline
\end{tabular}

Valores sugeridos por Ji-Yoo, Quantitative Lymphoscintigraphy for LymDhedema After Brest Cancer Suraerv. June $2015^{17}$.

primordial para un buen diagnóstico. Se debe preguntar sobre antecedentes y comorbilidades como: historia familiar, trauma, terapia por cáncer, radioterapia. Le sigue la evaluación de la extremidad afectada, variación en el tamaño, diámetro, localización de las cicatrices, heridas abiertas, sensibilidad, y características de la piel. La evaluación y medición de la circunferencia de las extremidades es el pilar del diagnostico y seguimiento en cuanto a la progresión o resolución de la enfermedad. Existen muchas herramientas disponibles para la medición del linfedema (desplazamiento de agua, medición de circunferencias, perimetría y bioimpedancia espectroscópica). En nuestra práctica, utilizamos la medición de la circunferencia anatómica. Se toman las siguiente medidas: A) $15 \mathrm{~cm}$ proximal al epicóndilo del húmero; B) el codo, específicamente el punto medio entre el epicóndilo medial y el epicóndilo lateral; C) $10 \mathrm{~cm}$ distal al epicóndilo lateral; D) la muñeca; E) la articulación metacarpofalángica ${ }^{17}$. Estas mediciones deben ser comparadas con las homólogas de la extremidad sana, que permite una medición cuantitativa del linfedema y un método clave y sencillo para evaluar el progreso con el tiempo.

Una vez hecho el diagnóstico de linfedema, se deben realizar otros test desarrollados para determinar la extensión de la enfermedad y el estadio funcional del sistema linfático. El gold standard para la evaluación del estado funcional del sistema linfático es la linfoscintigrafía. Esta utiliza una molécula unida al tecnecio $99 \mathrm{~m}$ que es inyectada en la dermis de los segundos espacios interdigitales del dorso de ambas manos con una aguja 25-gauge. Las imágenes subsecuentes revelarán el flujo dinámico, las áreas obstruidas y/o el contraflujo dérmico, que nos darán una adecuada orientación de cómo tratar a la paciente. Luego de la inyección del tecnecio $99 \mathrm{~m}$, el paciente debe estimular el sistema linfático apretando una pelota blanda durante 30 minutos. Se tomarán imágenes planas a los 30 minutos, 1 hora y 2 horas después de haber sido inyectado el colorante. La linfoscintigrafía es un estudio cualitativo y cuantitativo que utiliza un índice de asimetría cuantitativa (QAI, sus siglas en inglés). Existen regiones de interés (ROI) en ambas axilas, en donde se traza un círculo simétrico en ambos lados en el lugar donde se ubican los gangios linfáticos axilares regionales. En los ROI de ambas extremidades, el afectado y el sano, se trazan rectángulos que dividen las zonas. Debido a la excesiva absorción de los ganglios linfático del codo y a la alta captación 
TABLA 3. Grados de linfedema.

\begin{tabular}{|l|l|l|l|l|}
\hline Grado & Síntomas & Dif. circunf. (\%) & Linfoscintigrafía & Manejo \\
\hline 0 & Reversible & $<9$ & Oclusión parcial & CDP \\
\hline I & Leve & $10-19$ & Oclusión parcial & ALV, liposucción, CDP \\
\hline II & Moderado & $20-29$ & Oclusión total & TNVL + ALV \\
\hline III & Severo & $30-39$ & Oclusión total & TNVL + procedimientos adicionales \\
\hline IV & Muy severo & $\geq 40$ & Oclusión total & Procedimiento de Charles + TNVL \\
\hline
\end{tabular}

Dif. circunf. (\%): circunferencia de la extremidad lesionada restada de la circunferencia de la extremidad sana y dividida por la circunferencia de la extremidad sana medida $10 \mathrm{~cm}$ por encima y por debajo del codo, $15 \mathrm{~cm}$ encima y por debajo de la rodilla y 10 cm por encima del tobillo. CDP: fisioterapia descongestiva compleja. ALV: anastomosis linfaticovenosa. TNLV: transferencia de nódulo linfático vascularizado. Tomado de: Patel KM, Lin CT, Cheng MH. A prospective evaluation of lymphedema-specific quality-of-life outcomes following vascularizated lymph node transfer. Ann Surg Oncol 2015;22:2424-2430.

de radioactivo a nivel de la mano, en donde se inyecta el tecnecio 99, se divide al mismo en dos rectángulos: uno proximal (brazo) y uno distal (antebrazo). Quedan excluidos el codo y la mano. Los índices de asimetría de la región axilar y la extremidad superior se calcularon con el ROI radiactivo utilizando el siguiente fórmula, donde el conteo gamma fue el total de radiactivo captado por el ROI (Figura 2).

\section{$\mathrm{QAI}=($ captación en la región de interés afectada) /} (captación en la región de interés no afectada)

Existen valores de QAI de referencia para cada ROI. Estos fueron determinados en un estudio retrospectivo realizado por Ji-Na Yoo et al. ${ }^{17}$ (Tabla 2).

Este estudio revela que la linfografía es el mejor método para la evaluación funcional del linfedema y comparan la utilización de la medición de la circunferencia del miembro con la linfocintigrafía. Se llega a la conclusión que la medición de la circunferencia no es un método específico para evaluar al linfedema, pero es un método clínico simple, costo-efectivo y muy utilizado por nosotros. Hay ciertas variables que justifican esta limitación: la existencia de una mano dominante o mano hábil, el cambio de fluido, formas irregulares de las manos. La diferencia promedio entre miembros es 3\%. Algunos cambios de fluidos son inevitables debido al posicionamiento del paciente y la compresión externa a lo largo con irregularidades en la forma de la mano. Este método permite evaluar el volumen total de las extremidades, pero puede no reflejar los cambios en el volumen de fluido extracelular y por lo tanto es no es una medida específica de linfedema.

Otros métodos de diagnóstico incluyen la tomografía computarizada y la resonancia magnética, y un infrarrojo de red linfática de una inyección intradérmica de verde indocianina (ICG). Con la linfografia ICG se puede visualizar una imagen funcional en tiempo real del drenaje linfático. Después de la inyección de la indocianina, a través del uso de una cámara infrarroja se visualiza la presencia o ausencia fluorescente del drenaje de los canales linfáticos.

Utilizando los datos de la historia clínica, anamnesis y examen físico, procedemos a clasificar el linfedema en distintos grados. Existen varias clasificaciones aplica-

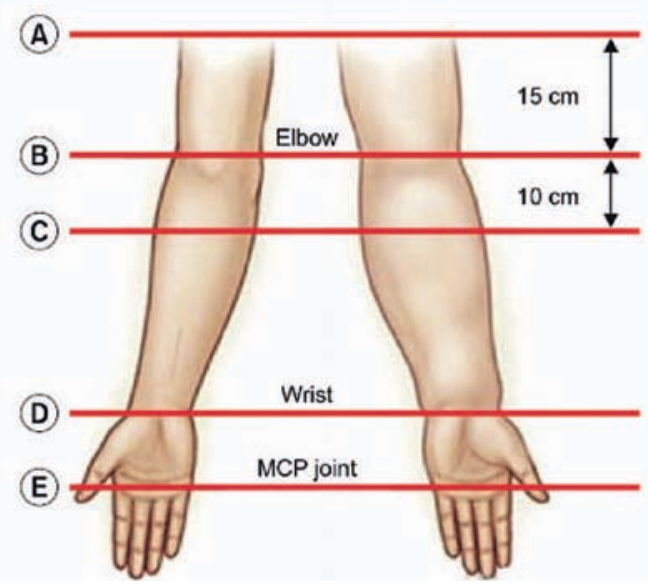

Figura 1. Medición de la circunferencia del miembro. Se toman las siguientes mediciones: A) $15 \mathrm{~cm}$ proximal al epicóndilo del húmero; B) el codo, específicamente el punto medio entre el epicóndilo medial y el epicóndilo lateral; C) $10 \mathrm{~cm}$ distal al epicóndilo la teral; D) la muñeca; E) la articulación metacarpofalángica ${ }^{17}$

bles. Nosotros tomamos la de la Sociedad Internaional de Linfología. Esta comprende 4 grados:

- Grado 0: Linfedema latente. Cuando existe flujo linfático posterior a la lesión, sin signos de edema o hinchazón;

- Grado 1: Linfedema reversible espontáneo. Definido como el edema o hinchazón que se mide y que se resuelve con elevación o terapia compresiva;

- Grado 2: Linfedema irreversible espontáneo. Es un edema progresivo que no responde a terapia conservadora;

- Grado 3: Elefantiasis linfostática. Es el estadio final, en el que un edema irreversible, hinchazón, fibrosis, y deposición grasa (adipogénesis), resultan en un engrosamiento firme de tejido con una hiperqueratosis.

Una modificación de esta clasificación es la propuesta por Cheng $\mathrm{MH}^{18}$ basada en la severidad de los síntomas, la diferenciación de circunferencias y las imágenes de la linfoscintigrafía para determinar el tratamiento. En este sistema, el linfedema está categorizado en 5 grados: Grado 0: reversible. Grado I: medio. Grado II: moderado. Grado III: severo. Grado IV: muy severo (Tabla 3). 

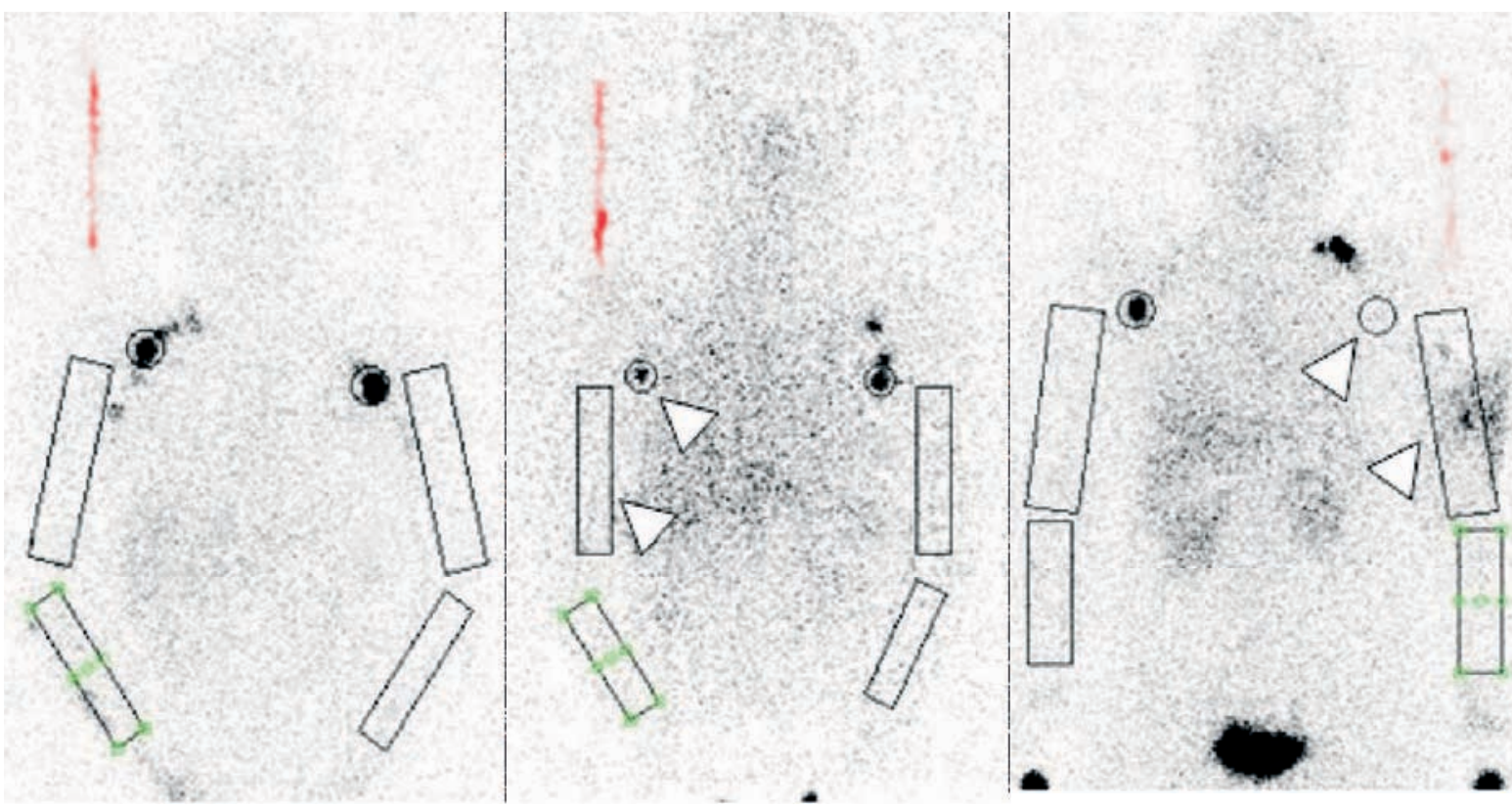

Figura 2. Imágenes típicas de una linfoscintigrafía cualitativo de la extremidad superior de una paciente con cáncer de mama cirugía que incluye disección de ganglios linfáticos axilares (LN). La LN axilar y el área sintomática de la extremidad superior se analizaron cualitativamente tanto en el lado afectado (flecha) como en el lado no afectado. (A) El patrón normal muestra captación simétrica de tecnecio 99m en la LN axilar y la extremidad superior, (B) el patrón de función disminuida mostró una disminución de la captación en tanto el LN axilar como el miembro superior (punta de flecha), y (C) el patrón de obstrucción mostró poca captación en la axila.LN y captación altamente aumentada en la extremidad superior (punta de flecha). Revista ARM (Annals of Rehabilitation Medicine; Quatitative lymphoscintigraphy for Lymphedema Afer Brest Cancer Surgery; Ji-Na Yoo, et al; June 26 2015).

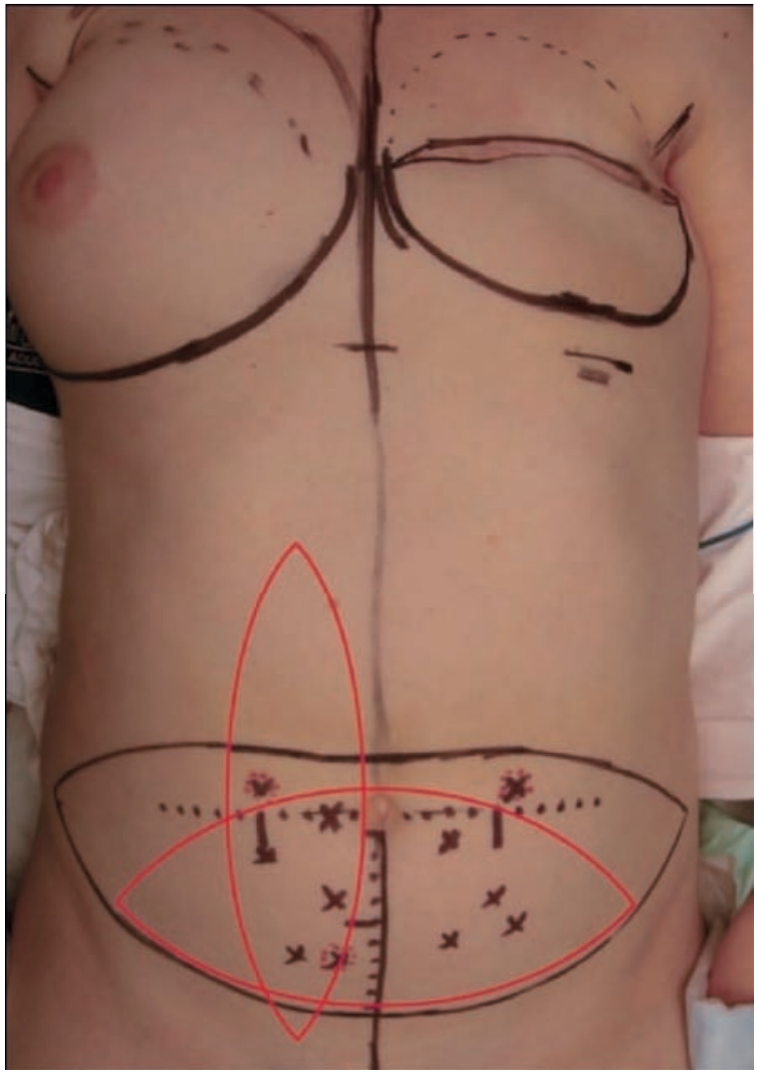

Figura 3: Diseño de colgajo DIEP. Las cruces $(x)$ muestran las proyecciones de las perforantes.

\section{TRATAMIENTO}

Con el conocimiento del proceso de la enfermedad, las manifestaciones clínicas, modalidades diagnósticas y grado de linfedema, se debe saber cuándo iniciar el tratamiento de la enfermedad. Lo primordial es limitar la morbilidad de la paciente, mientras mejoramos la función y calidad de vida. Es decir, debemos disminuir el edema, promover la higiene, reducir las infecciones, promover movilidad, entre otros.

Existen 2 tipos de tratamientos para el linfedema: el tratamiento conservador y el tratamiento quirúrgico.

El tratamiento conservador es el tradicional, y que en principio se aplica a todos los grados de linfedema. Está representado principalmente por la terapia descongestiva compresiva, mediante el uso de fajas compresivas, ejercicios terapéuticos, masajes linfáticos descompresivos manuales, y una higiene meticulosa. Otras opciones son la compresión neumática, terapia láser.

El tratamiento quirúrgico del linfedema tiene registros de inicio ya en el año 1901, cuando Charles realizó una exéresis de tejido para tratar un linfedema escrotal. Se describieron varias técnicas a través del tiempo. Las opciones quirúrgicas de tratamiento se dividen en: procedimientos de exéresis y procedimientos fisiológicos. Dentro de los procedimientos de exéresis están: procedimiento de Charles, resección en cuña y la liposucción. El procedimiento de Charles, descrito en 1912, comprende la exéresis de piel y tejidos blandos de la extre- 


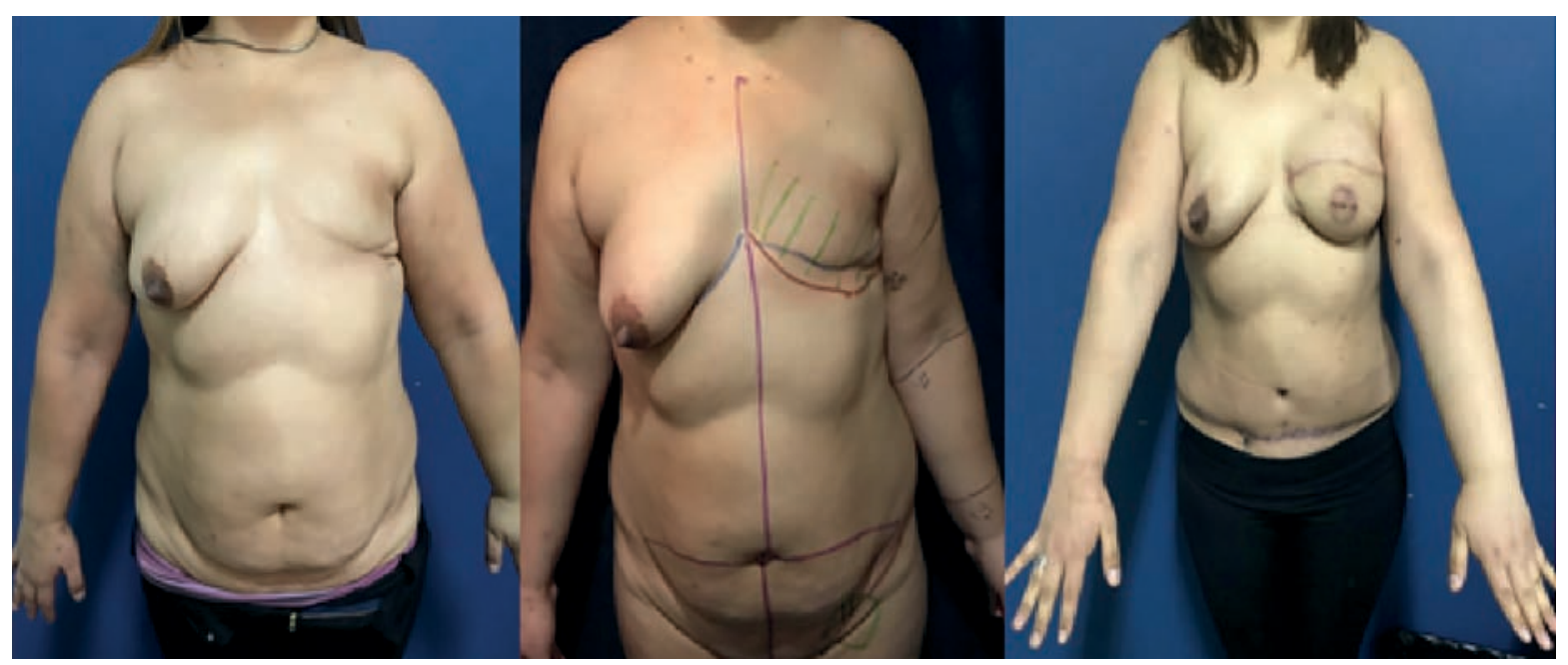

Figura 4.

midad afectada por debajo de la fascia profunda y empleo de piel como injerto para cobertura. Debido a la desfiguración natural del procedimiento, el procedimiento de Charles está reservado solo para los casos muy severos de linfedema. La resección en cuña es la exéresis de tejidos blandos y piel por encima de la aponeurosis profunda con cierre directo.

La liposucción, aspiración bajo presión negativa, es la que otorga mejores resultados en el linfedema, disminuyendo el edema y tasas de infección en la extremidad con comprometida.

Dentro de los procedimientos fisiológicos, y con el advenimiento de las técnicas microquirúrgicas, se tienen nuevas opciones de manejo del linfedema: anastomosis linfaticovenosa (ALV), transferencia de nódulo linfático vascularizado (TNLV). Estas cirugías tienen el objetivo de restablecer la alteración que desencadena el linfedema, a través de un bypass de las áreas de linfáticos dañados hacia el sistema venoso o mediante el reemplazo de los canales y nódulos linfáticos perdidos, respectivamente.

La ALV utiliza la fluorescencia (verde de indocianina) inflarroja se debe identificar un vaso linfático adecuado. Es decir, se visualizaran coloreados los vasos linfáticos funcionantes. Luego, se identifica una adecuada vena para la anastomosis. Por lo general, se realizan varias anastomosis en varios sitios de la extremidad afectada.

El otro procedimiento quirúrgico fisiológico es la TNLV. Este es el que realizamos en el servicio de nuestro hospital y es uno de los últimos avances en la terapia quirúrgica para linfedema. Se trata de un trasplante de nódulos linfáticos junto con una paleta de piel vascularizado, en áreas de linfedema. Se selecciona el área donante. Nosotros utilizamos la ingle. Una vez obtenido el colgajo donante para la transferencia de nódulos linfáticos vascularizados, se debe seleccionar la zona receptora para realizar la transferencia, evaluando varios factores: localización del linfedema (extremidad superior, inferior), disponibilidad de vasos receptores, cicatrices quirúrgicas previas, resultados estéticos, y la experiencia del cirujano con el sitio receptor. Nosotros utilizamos la axila.

En el servicio también realizamos otro método quirúrgico aun más complejo. Se trata de la realización de la reconstrucción mamaria y transferencia ganglionar vascularizada en un mismo tiempo quirúrgico. Esto es lo que actualmente estamos realizando. Se realiza elevación y disección de colgajo DIEP, cuyo pedículo se anastomosa a la arteria mamaria interna a nivel del segundo espacio intercostal, en el lado contralateral del pedículo vascular del DIEP. Se realiza disección de ganglios inguinales superficiales junto a su pedículo vascular, el cual será anatomosado a los vasos receptores en la región axilar. El paciente es manejado de acuerdo a protocolos establecidos para reconstrucción con colgajo libre microvascularizado. Este tipo de cirugías es el denominado colgajos en serie.

\section{TÉCNICA QUIRÚRGICA}

A continuación detallaremos paso a paso el procedimiento completo realizado en nuestro servicio.

\section{- Preparación preoperatoria}

EI día previo a la cirugía ingresaremos a la paciente, tras una ducha y rasurado del $1 / 3$ superior del pubis, realizaremos un estudio de las perforantes mediante Doppler y el marcado del colgajo. Si no se dispone de un duplex-Doppler que nos pueda dar una máxima informacióń podemos utilizar un Doppler de ultrasonidos portátil con una sonda de $8 \mathrm{mHz}$, de esta forma localizaremos las perforantes de mayor flujo sobre el territorio a utilizar. Habitualmente, las perforantes de mayor calibre se suelen situar en la fila medial y a nivel paraumbilical.

\section{- Diseño del colgajo}

Los factores que intervienen en el diseño del colgajo son: 


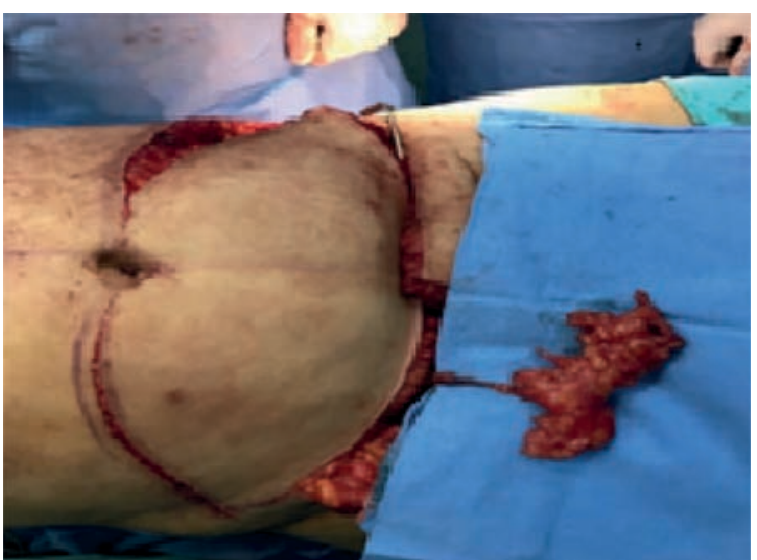

Figura 5.

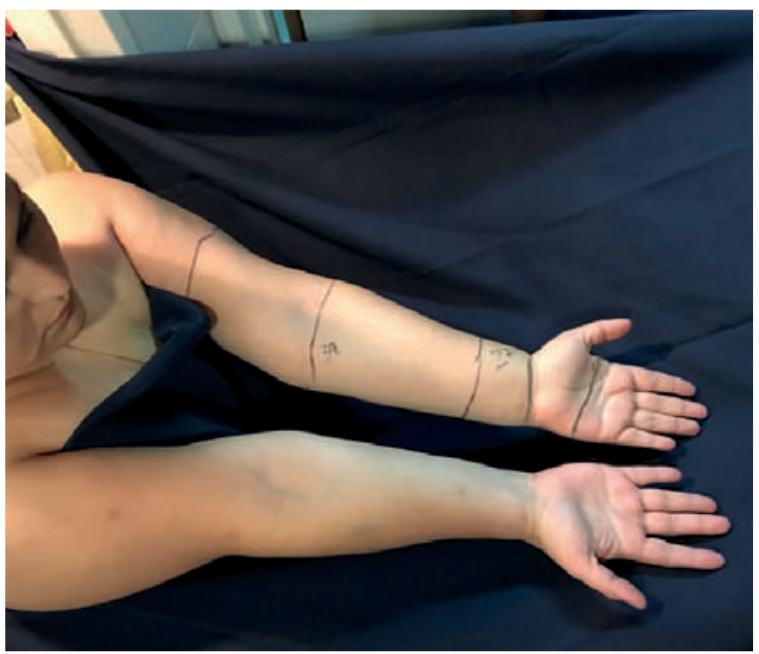

Figura 7. Linfografia cualitativa. Secuencia de de la paciente del Caso clinico 1. Se muestra en el primer recuadro la imagen preoperatoria. Los dos siguientes son de Noviembre de $2017 y$ Mayo 2018, respectivamente (postoperatoria).

- Localización de la perforante elegida y de su trayectoria a través del músculo.

- Del conocimiento de que la zona IV será la más pobremente vascularizada y que casi siempre va a ser descartada.

- La existencia de cicatrices abdominales que puedan afectar el diseño, como por ejemplo medianas infraumbilicales.

- EI tamaño del colgajo que precisamos para recrear una mama lo más parecida posible a La contralateral.

Todos estos factores deben ser considerados dentro de un diseño de dermolipectomia abdominal estética para así poder conseguir una buena reconstrucción mamaria con un excelente resultado estético abdominal. Realizaremos el marcado con la paciente de pie. El diseño del colgajo tiene forma elíptica. Los limites del colgajo pueden variar ligeramente pero irán del surco suprapubico hasta por encima del ombligo y lateralmente hasta las espinas iliacas antero-superiores. Las dimensiones del colgajo oscilan generalmente entre los 12 a $14 \mathrm{~cm}$ de alto y los 30 a $45 \mathrm{~cm}$ de ancho. En

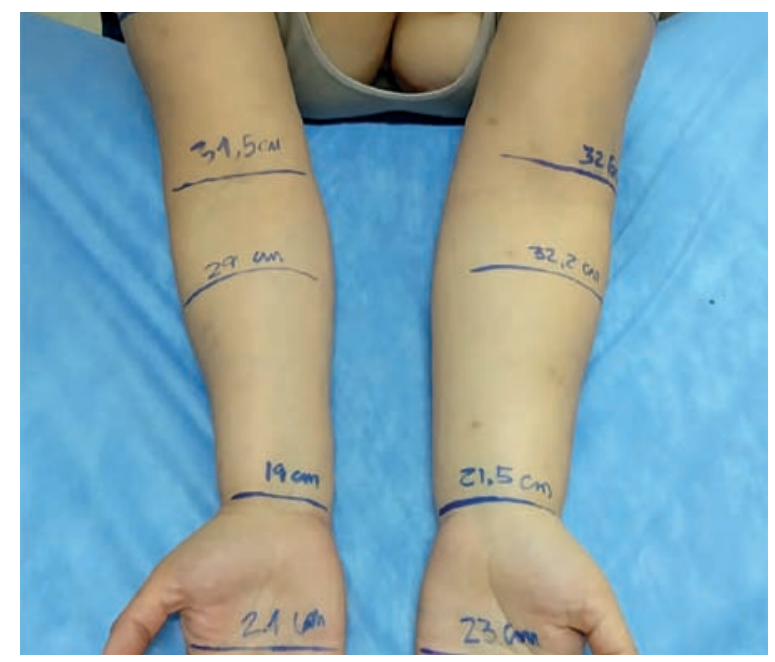

Figura 6.

la reconstrucción inmediata marcaremos el surco submamario, el borde superior de la mama, el pliegue axilar anterior, la cicatriz de la biopsia y el complejo areola pezón (Figura 3).

En la reconstrucción diferida, el surco submamario y el borde superior de la mama serán marcados en espejo a partir de la mama contralateral. También marcaremos el pliegue axilar anterior y la línea media de la mama. Solo resta mencionar que solemos hacer una reserva de sangre autóloga de una unidad, que se extrae a las pacientes unas 3 semanas antes de la intervención.

Con el paciente en decúbito supino y con los brazos pegados al tronco, iniciaremos las incisiones cutáneas siguiendo el diseño marcado. Aislamos el ombligo mediante una incisión circunferencial disecándolo hasta la fascia. La incisión superior abdominal la realizaremos a bisel para así poder dejar la mayor cantidad de tejido graso al colgajo.

Mientras efectuamos la incisión abdominal inferior debemos intentar localizar la vena epigástrica inferior superficial. Si encontrásemos una arteria epigástrica inferior superficial de suficiente calibre podríamos elevar el colgajo con estos vasos (SIEA), pero en la práctica es poco probable ya que la arteria es muy inconstante. En cambio la disección de unos centímetros de la vena epigástrica inferior nos puede ser útil como un drenaje venoso en casos de congestión venosa del colgajo, ya sea por insuficiencia de las venas perforantes o por trombosis venosa.

Tras completar las incisiones hasta la fascia, iniciaremos la elevación del colgajo a nivel contralateral al pecho a reconstruir. De esta forma podemos trabajar a dos equipos simultáneamente de una forma cómoda, y al rotar el colgajo $180^{\circ}$ durante la transposición al tórax nos sitúa la perforante tan lateral cómo es posible. Esto nos permitirá una sutura nerviosa más fácil entre la rama anterior del $4^{\circ}$ nervio intercostal y la rama sensitiva del nervio segmentario cuando queremos reinervar el colgajo. También nos permitirá una sutura más cómoda entre las venas concomitantes me- 


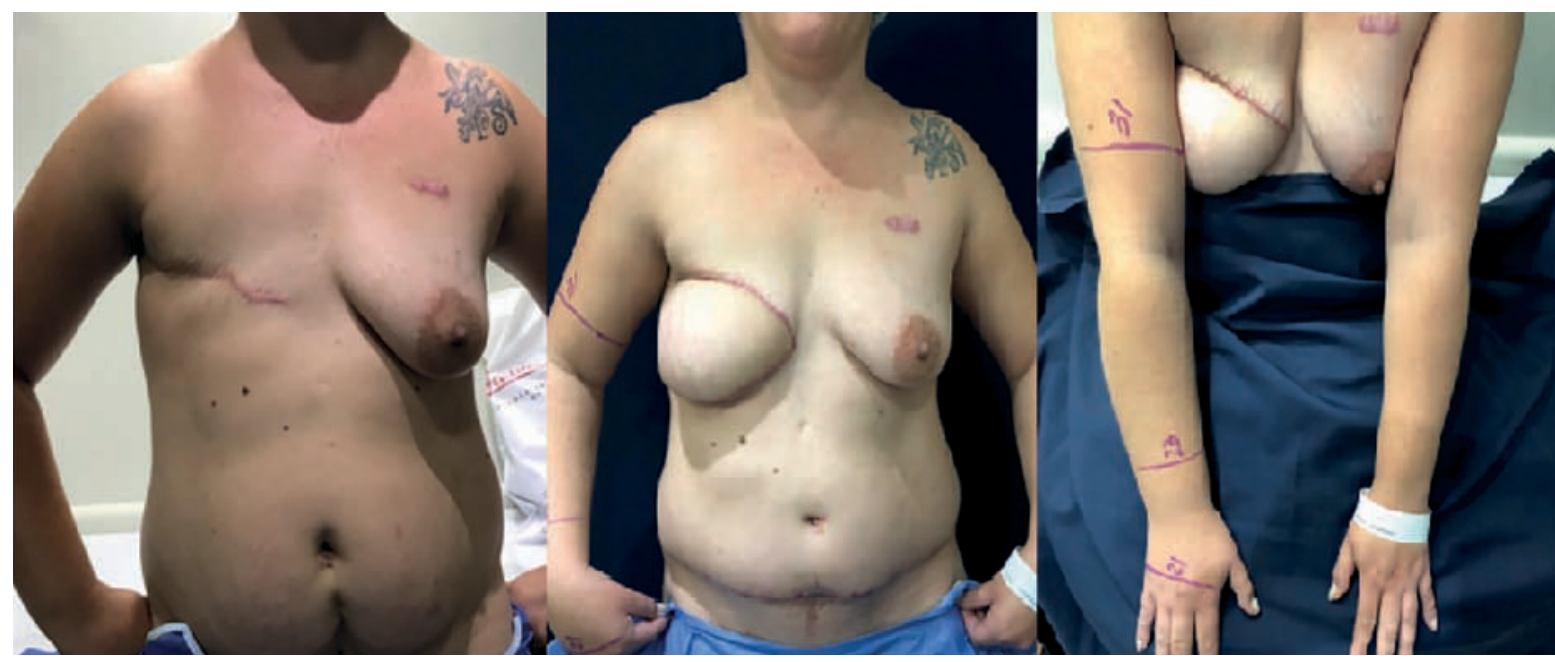

Figura 8. Linfografia cuantitativa. Secuencia de la paciente del Caso clinico 1. Se muestra en el primer recuadro la imagen preoperatoria. En los dos siguientes se muestran las imágenes postoperatorias de Noviembre de 2017 y de Mayo de 2018.
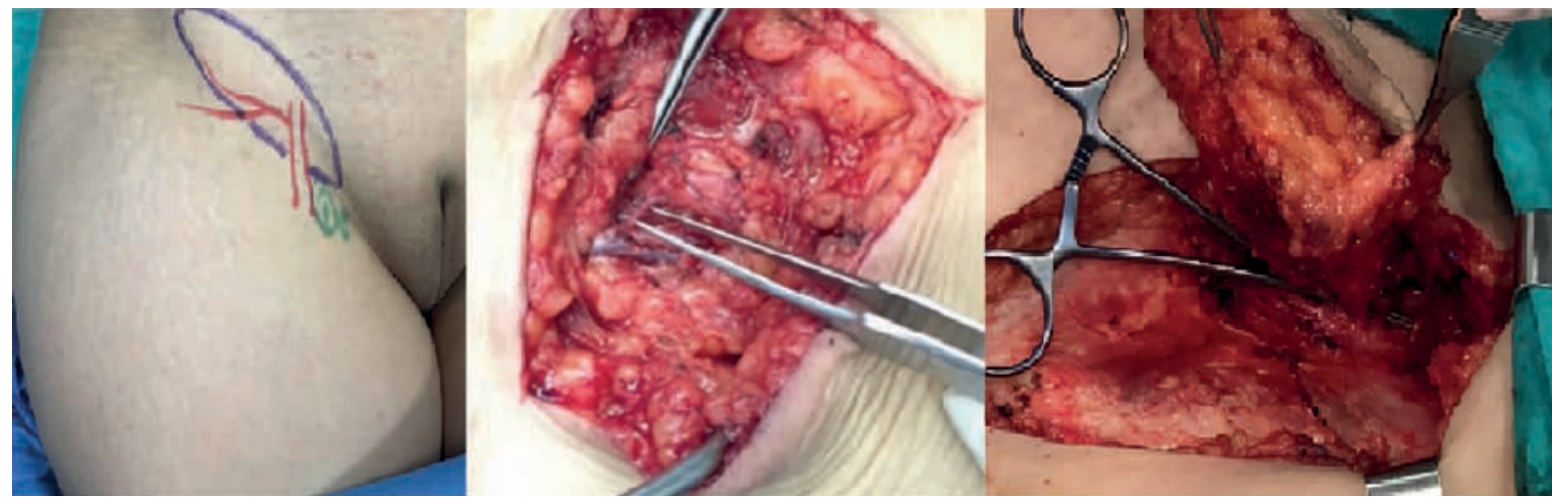

Figura 9.

diales de la mamaria interna y de la epigástrica inferior profunda, que suelen ser las de mayor calibre. A su vez sitúa la parte del colgajo con mayor grosor de tejido (zonas I y II) a nivel más medial, contribuyendo a poder lograr una mejor proyección de la neomama.

La elevación se inicia desde el extremo, sobre la fascia del oblicuo externo, una vez alcanzado el borde lateral del músculo recto anterior debemos tener un máximo cuidado en la disección para no cortar las perforantes que irán apareciendo, y que orientativamente habremos localizado con el doppler. Nosotros aconsejamos realizar la disección a tijera con la técnica del acueducto y utilizar siempre las pinzas bipolares para coagular. Si encontramos una perforante de buen calibre, con solo una es suficiente, debemos siempre intentar valorar la calidad de las venas, ya que de haber insuficiencia la mayoría de las veces será venosa. Si precisamos de un gran colgajo o el tamaño de las perforantes es discreto, deberemos elegir dos o tres de ellas, podrá ser en el mismo recorrido para así no tener que cortar ningún puente muscular. Las perforantes mediales suelen tener un mejor flujo aunque obligan a una disección más larga, ya que tienen un trayecto intramuscular más largo y con más ramas colaterales.
Una vez seleccionada la perforante, la disección suprafascial debe ser muy cuidadosa, dejando totalmente esqueletizada la perforante desde su salida a través de la fascia hacia la entrada al tejido graso. Posteriormente tenemos dos posibilidades para iniciar su disección: podemos resecar un pequeño ojal de fascia que quedará adherida a la perforante o podemos buscar la hendidura natural por la cual la perforante atraviesa la fascia. Visualizando el músculo abrimos una incisión longitudinal sobre la fascia en dirección hacia la entrada de la epigastrica inferior profunda en el borde lateral del músculo. Liberamos bien el plano entre el músculo y la fascia alrededor de la perforante, he iniciamos la disección intramuscular separando las fibras musculares siguiendo su sentido natural.

Con la ayuda de las pinzas bipolares y de pequeños hemoclips iremos aislando la perforante elegida de las otras ramas musculares. Deberemos tener una especial atención en la localización de los nervios segmentarios motores, los cuales deberán disecarse y preservarse. Si hemos elegido más de una perforante deberemos intentar unir los diferentes trayectos hasta encontrar la epigástrica inferior profunda pero siempre evitando seccionar grandes fragmentos de músculo y sin seccionar los nervios segmentarios motores. En el caso extremo de tener que cortar algún nervio, deberá resuturarse. 


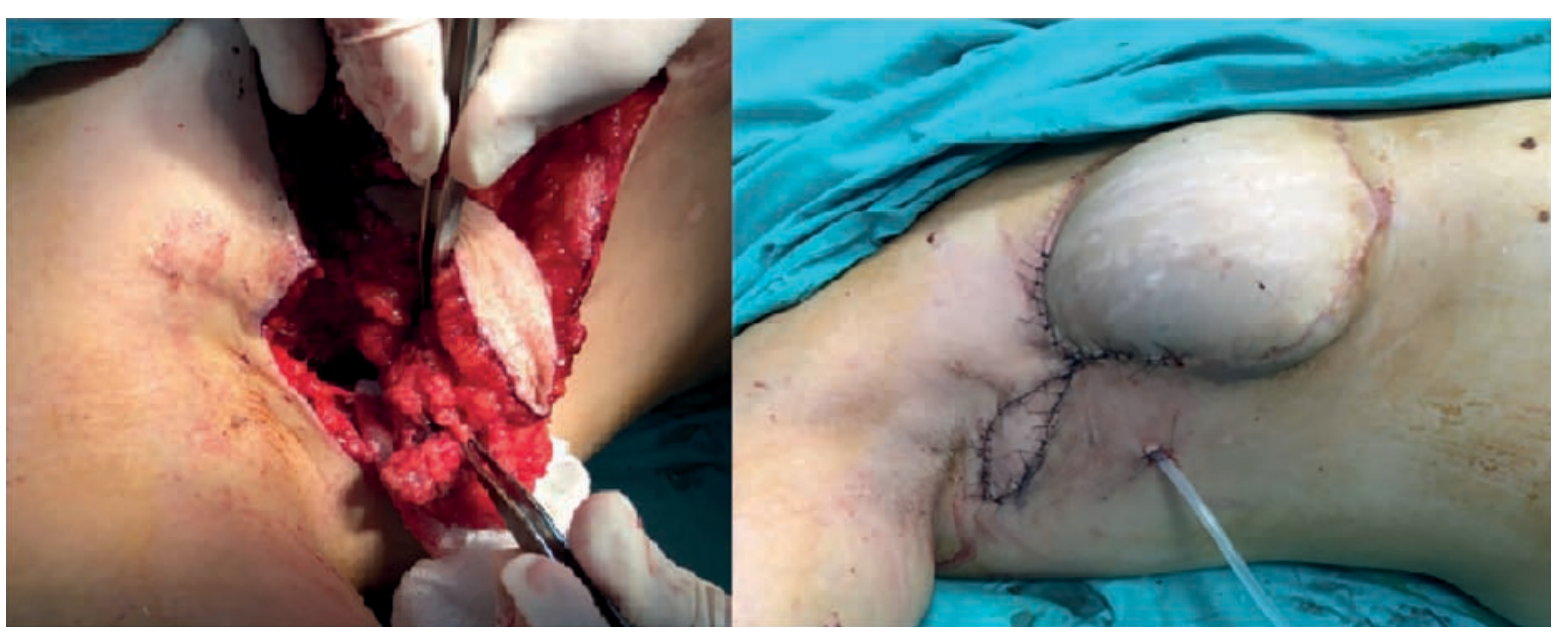

Figura 10. Caso clínico 2. A) Marcación del colgajo inguinal con paleta de piel para la TNLV. Se observa la proyección de la Arteria Femoral Profunda, junto con su rama, la Arteria Circunfleja llíaca Superficial (la cual es utilizada para la anastomosis) en rojo. B) Se observa la Rama Circunfleja llíaca Superficial elevada en la pinza. C) Colgajo inguinal junto con los ganglios. Se observa la Rama Circunfleja llíaca Superficial demostrada por la pinza. D) Anastomosis del Colgajo inguinal en la axila. E) Posoperatorio inmediato. Se observa el colgajo DIEP en la mama vital y el colgajo Inguinal a nivel axilar.

A nivel de la parte posterolateral del músculo encontraremos la epigástrica inferior profunda, y tras comprobar la continuidad de la perforante hasta ella procederemos a seccionar las otras ramas del pedículo vascular dejando totalmente aislada y esqueletizada la perforante y la epigástrica inferior profunda.

Una vez que tenemos todo el colgajo elevado, únicamente conectado a la epigástrica inferior profunda a través de la o las perforantes elegidas, lo reposicionaremos sobre el abdomen fijándolo a nivel de la incisión inferior. El dejar el colgajo totalmente desconectado del aporte vascular excepto a través de la perforante mientras disecamos la parte superior del abdomen como hacemos en la dermolipectomia abdominal nos permitirá definir claramente la percusión del territorio cutáneo y nos ayudará a definir cuanta zona IV o II podemos conservar.

\section{- Preparación de los vasos receptores:}

Si se efectúa una reconstrucción mamaria inmediata con vaciamiento axilar utilizaremos como vasos receptores los toracodorsales, por encima de la salida de la rama del serrato. En el resto de casos utilizaremos los vasos mamarios internos.

Los motivos por los cuales preferimos la mamaria interna son:

Porque son unos vasos muy constantes.

A nivel del tercer cartílago intercostal la mayoría de veces tienen un calibre adecuado permiten una posición de trabajo muy cómoda.

Muy raramente estarán afectados por radioterapia. La posición en la cual tendremos el colgajo después de la anastomosis ofrece la posibilidad de una correcta remodelación del tejido al dar una mayor proyección medial el movimiento inspiratorio de la cavidad torácica ejerce un efecto de succión a nivel de la vena que ayuda al retorno venoso.
Accederemos a la disección del tercer cartílago costal a través de la incisión realizada tras resecar la cicatriz de la mastectomía. Debemos separar la fibras del pectoral disecando un espacio que ira de la articulación condroesternal a la unión condrocostaI, realizaremos una incisión en $\mathrm{H}$ sobre el pericondrio y pasaremos a separarlo del cartílago con mucho cuidado, para dejar entero el pericondrio de la parte posterior debajo del cual tendremos la mamaria interna. Cortaremos el cartílago a nivel de la unión condrocostaI, lo desarticularemos a nivel condroesternal y lo retiraremos. Abriremos el pericondrio posterior, encontrándonos los vasos mamarios internos, los cuales tras ligar las pequeñas ramas que puedan tener, los seccionaremos a nivel distal y los prepararemos para la anastomosis.

\section{- Anastomosis vascular microquirúrgica:}

Seccionaremos el pedículo epigastrio más o menos proximal en función del tamaño de los vasos que necesitemos. Transferiremos el DIEP al tórax, siempre evitando que el pedículo se rote. A su vez el colgajo será rotado $180^{\circ}$, de modo que la zona IV será la más medial. Fijaremos el colgajo al tórax y procederemos a realizar una anastomosis que en la mayoría de los casos podrá ser termino-terminaI con nylon $8 / 0 \mathrm{y} / \mathrm{o} 9 / 0$ con microscopio de aumento 16x. Se comprueba vitalidad del colgajo, la anastomosis arterial y el drenaje venoso. Se coloca drenaje de tipo aspirofusor. Cierre con nylon 3.0.

\section{- Transferencia de nódulo linfático vascularizado:}

Se realizò de forma inmediata a la reconstrucción junto con el colgajo DIEP en un mismo tiempo quirúrgico, o en un segundo tiempo diseñando un colgajo inguinal que se lleva a la axila. Se utiliza como zona dadora, un colgajo inguinal junto con sus ganglios linfáticos. Se inicia ubicando el pulso femoral y asi la ubi- 
cación de la arteria femoral común. Se diseña una paleta a nivel inguinal, paralelo al ligamento inguinal y lateral al paquete vasculonervioso femoral. Esto difiere con el diseño original del colgajo inguinal. Los ganglios linfáticos regionales son usualmente no palpables a ese nivel. Se realiza una incisión en el margen superior del colgajo y se busca la arteria y la vena circunfleja ilíaca superficial de distal a proximal. Se secciona una gran cantidad de tejido, sin disecar exhaustivamente, con motivo de mantener la integridad de los nódulos y vasos linfáticos. En algunas ocasiones no llevamos la paleta de piel. El motivo de incorporar la pastilla de piel seria no solo para tener un testigo del colgajo, sino como para aliviar tensiones en la zona receptora. Se transfiere junto con el colgajo DIEP hacia la axila, para anastomosarse con los vasos axilares.

\section{RESULTADOS}

Los detalles clínicos de cada paciente están detallados en la Tabla 1.

Todos los colgajos vivieron. Como complicaciones posoperatorias se registraron cuatro seromas en la zona receptora, una dehiscencia de herida quirúrgica y una infección en la zona receptora. La variable utilizada por nosotros fue la circunferencia del miembro afectado en comparación con el miembro sano, del pre- y posquirúrgico. La linfografía y la sintomatología del paciente fueron otras dos variables que se tuvieron en cuenta a la hora del seguimiento.

En un seguimiento promedio de 10,43 meses (rango de 3 a 27 meses), se encontró una reducción de la circunferencia del miembro afectado en las 16 pacientes (100\%). La tasa de reducción de la circunferencia del miembro fue de un $27,78 \%$.

La linfografía mostró en todas las pacientes una disminución del QAI axilar. En 10 pacientes a pesar de haber disminuido, siguió mostrando un valor de patrón de obstrucción. En el resto, el valor de QAI se normalizó.

Ninguna de las pacientes volvió a presentar episodios de celulitis en el miembro afectado. Los síntomas que menos mejoraron fueron la pesadez y el dolor.

\section{CASO CLÍNICO 1 (PACIENTE 13) (TABLA 1)}

Paciente femenina de 36 años, ingresa al servicio de $\mathrm{Ci}$ rugía Plástica del Hospital Santojanni derivada del servicio de Ginecología de la misma institución tras haberle realizado tratamiento conservador con radioterapia con posterior mastectomía total de mama izquierda. Dicho tratamiento finalizó en junio de 2015. Acude a la consulta con propósito de reconstrucción mamaria y en pos de resolución de linfedema secundario. Se realiza historia clínica detallada obteniéndose los siguientes datos positivos: linfedema en miembro superior izquierdo secundaria al tratamiento del cáncer de mama. Presenta sintomatología asociada al linfedema: edema, pesadez (todos los días, en todo momento del día), invalidez (imposibilidad de agarrar y sostener objetos con la mano afectada) y dolor (7/10) de 24 meses de evolución, no presentó infección en ninguna ocasión. Se realizan mediciones de la circunferencia del miembro superior con linfedema y del miembro superior sano. Se solicita una linfografía preoperatoria que se realiza en junio de 2016, y su resultado arroja una restricción a nivel del brazo. Presenta QAI axilar: 0,07 (Figuras 7 y 8).

Presenta linfedema grado II.

Se plantean las opciones reconstructivas y se decide la realización de colgajo DIEP + transferencia de nódulo linfático vascularizado de la ingle a la axila. Se realiza dicho procedimiento en serie, es decir en un solo tiempo quirúrgico.

Se obtuvieron los siguientes resultados. No hubo morbilidad en el área dadora. La sintomatología mejoró. El dolor cesó, no así la pesadez. No volvió a repetir episodios de celulitis. Se realizaron dos linfografias postoperatorias. Se observó una disminución del QAI de la axila de 0,01. La circunferencia del miembro afectado posoperatoria (codo) fue de $32,6 \mathrm{~cm}$, dándose una tasa de reducción de la circunferencia del miembro del $26,67 \%$, luego de un seguimiento de 27 meses (Figu$\operatorname{ras} 4,5$ y 6$)$.

\section{CASO CLÍNICO 2 (PACIENTE 15) (TABLA 1)}

Paciente femenina de 47 años, derivada del servicio de Ginecología tras presentar secuela de mastectomía en mama derecha. Tratamiento realizado en agosto de 2014. Acude a la consulta con motivo de reconstrucción de mama. Se realiza reconstrucción con colgajo DIEP en enero de 2017. Evoluciona con linfedema, sufriendo síntomas como pesadez y celulitis en una ocasión. Enfermedad de base: hipotiroidea en tratamiento con t4; Se realizan mediciones de circunferencia del miembro superior afectado y del sano, $21 \mathrm{~cm}$ y $23 \mathrm{~cm}$ respectivamente. Se realiza linfografía preoperatoria. Se realiza una transferencia de nódulos linfáticos vascularizados, junto a paleta de piel. Se utiliza como zona dadora la ingle y la axila como zona receptora.

Se obtuvieron los siguientes resultados, con un seguimiento de 11 meses. Se redujo la circunferencia del miembro afectado en un $25 \%$, según la tasa de reducción del miembro. Con un valor de circunferencia del miembro afectado posoperatorio de 22,5 $\mathrm{cm}$. (Figuras 9 y 10).

\section{DISCUSIÓN}

En 1912, Charles, fue el primero en hablar de tratamientos quirúrgicos del linfedema. Proponía una cirugía de citorreducción agresiva, en la cual se realizaba una resección de toda la piel y el tejido blando que se encontraba por encima de la fascia profunda. Luego, esto se cubría con un injerto de piel ${ }^{21}$. 
En el año 1927, Sistrunk describió por primera vez un procedimiento quirúrgico para el linfedema de las extremidades superiores relacionada con el cáncer de mama e intentó crear una conexión espontánea entre los vasos linfáticos superficiales y profundos mediante la extirpación del exceso de piel y tejidos blandos, incluida la fascia profunda por medio de una incisión en forma de huso en la extremidad medial ${ }^{24}$. Unas décadas más tarde, Thompson realizó una transposición linfática en el cual se levantaba un colgajo rectangular en toda la longitud del brazo y la punta del colgajo se colocaba al lado del paquete vasculonervioso, como intento de generar un puente entre el sistema linfático superficial y profundo ${ }^{22,23}$. Sin embargo, no existen evidencias de que estos procedimientos hayan tenido éxito. En 1989, O’Brien et al. reportaron un tratamiento quirúrgico mediante liposucción. Este mismo, si bien reduce el volumen del miembro afectado, también produce daño en los vasos linfáticos residuales, pudiendo así exacerbar el linfedema ${ }^{25,26}$. Baumeister, Siuda, Ho et al. informaron el uso de un bypass linfático-linfático para tratar el linfedema de las extremidades superiores, en el que se usaron vasos linfáticos sanos del muslo medial como injertos. El injerto se inserta debajo de la piel del hombro para crear rutas de derivación linfática entre la parte superior del brazo y la región supraclavicular. Los vasos linfáticos en cada extremo del injerto se identifican y se anastomosan con vasos linfáticos del receptor en el cuello y la parte superior del brazo, de acuerdo con la dirección del flujo linfático en los vasos donantes. Sin embargo, la recolección de los vasos linfáticos deja una cicatriz larga en el sitio del donante y puede provocar linfedema en la pierna del donante ${ }^{27}$. Campisi realizó un injerto de interposición de vena entre los haces de vasos linfáticos por encima y debajo del sitio de bloqueo linfático, generando un bypass de la obstrucción $^{28,29}$. En 1953, Sir Harold Gilles describió el colgajo de interposición para el tratamiento de linfedema de extremidad inferior. Luego, en 1996, Goldsmith describió la utilización del colgajo de omento mayor, rico en tejido linfático, para tratamiento del linfedema. En 1963, Laine and Howard investigaron y describieron el bypass linfaticovenoso en ratas. Utilizaron una técnica microquirúrgica para anastomosar vasos linfáticos periféricos a venas adyacentes para drenar el exceso de líquido desde la extremidad linfedematosa al sistema venoso. Treinta años más tarde, Yamada realizó procedimientos similares en perros y en 1969 publicó la utilización el bypass linfovenoso para tratar el linfedema de las extremidades inferiores en humanos; desde entonces, otros han refinado la técnica $^{31}$. Koshima en el año 2000 publicó su experiencia ccn 18 pacientes en anastomosis linfoveno- sas en miembro superior para tratamiento del linfedema, con buenos resultados ${ }^{11}$. Chang, en el año 2013 reportó 100 casos, obteniendo como resultado una reducción significativa del volumen del miembro afectado ${ }^{12}$. En el año 1990, Becker publica un trabajo de transferencia de nódulos linfáticos, habiéndose reportado algunos trabajos previos en animales. Cuatro años más tarde, Saariso publica su trabajo de reconstrucción mamaria microquirúrgica junto con el trasplante de nódulos linfáticos vascularizados.

Como se mencionó anteriormente existen dos tratamientos quirúrgicos fisiológicos para tratar el linfedema. La Anastomosis Linfático-Venosa fue descripta por primera vez en humanos en el año 1969. Yamada fue quien lo publicó, luego de varias publicaciones experimentales en animales. El procedimiento fue dirigido a superar la obstrucción en el sistema linfático mediante desviación de la linfa proximal a la obstrucción, hacia el sistema venoso. Este procedimiento ha sido desarrollado para cualquier estadio de linfedema y también como profilaxis de linfadenectomía. Es mucho más conveniente y más efectivo, cuanto más temprano sea realizado. Considerando la localización, muchos cirujanos indican realizar los bypass en múltiples niveles de la extremidad afectada (p. ej.: muñeca, antebrazo, brazo), mientras otros indican que es necesario realizar múltiples anastomosis. En teoría esto puede incrementar la oportunidad del éxito del shunt, pero esto puede resultar en una ruptura ya limitada del sistema linfático. La anastomosis linfaticovenosa no recibe el flujo linfático distal, como incompetencia válvula linfáti$\mathrm{ca}$, resultando en linfedema. La desviación de realizar anastomosis terminoterminal versus terminolateral o lateralterminal de la anastomosis linfaticovenosa, está aun muy discutida.

Cualquiera sea la técnica empleada, existen factores que deben ser considerados porque influyen en el éxito de la anastomosis. Primero, un adecuado vaso linfático debe ser identificado. Esto puede ser realizado mediante la inyección de colorante (azul patente). La fluorescencia infrarroja con verde indocianina pueden ser usadas para ver la red en mapa de los canales linfáticos. Al examen el colorante será visualizado viajando a través de los linfáticos funcionantes. La pérdida de la funcionalidad linfática y/o los linfáticos, localizados en el tejido subcutáneo profundo, imposibilitan la identificación por este método. Segundo, se debe identificar una adecuada vena para la anastomosis, que debe ser de diámetro y tamaño compatible, localización apropiada con mínimo contraflujo cuando sea dividido. Las grandes venas pueden incrementar la presión intraluminal que puede resultar en reflujo venoso hacia los canales linfáticos posteriores 
a la anastomosis. Koshima et al. tienen el objetivo de superar estos problemas con el uso de las técnicas de supermicrocirugía, cuando el tamaño de los canales linfáticos y venas usados son menores que $0.8 \mathrm{~mm}$ en diámetro ${ }^{11}$. Y finalmente, los vasos linfáticos son de paredes extremadamente delgadas y colapsan fácilmente. El mantenimiento prolongado de la permeabilidad de la anastomosis linfaticovenosa no puede ser asegurada, sin embargo, la permeabilidad inmediata puede ser demostrada con azul patente o la linfografía. La mejoría del linfedema siguiente a la anastomosis linfaticovenosa depende de los tres factores mencionados. Aun con las variaciones de los significantes en las técnicas quirúrgicas, la anastomosis linfaticovenosa ha establecido como una herramienta fundamental en el manejo del linfedema. Chang et al. publicaron recientemente un análisis prospectivo de anastomosis linfaticovenosa en 100 pacientes, con un año de seguimiento post operatorio, mostrando una gran mejoría de la reducción del volumen del $61 \%$ en un estadio primario de linfedema de extremidad superior y un $17 \%$ en estadio avanzado de linfedema. Se observó una gran mejoría en un estadio temprano de casos de linfedema de extremidad comparando con la mejoría en meseta después del año, otros estudios han corroborado estos hallazgos, mientras también se notaron disminución del volumen, disminución de la tasa de infecciones y liberación del uso de elementos compresivos posteriores a la anastomosis linfaticovenosa. Las complicaciones de este procedimiento son mínimas e inusuales, e incluyen infección, fístula linfática y problemas de herida ${ }^{12}$.

Por otro lado, la transferencia de nódulos linfáticos vascularizados promete buenos resultados, con inentendibles preguntas acerca del mecanismo de acción, la elección del sitio donante, elección de la zona receptora y los cuidados posoperatorios.

Aun se desconoce el mecanismo por el cual la TNLV mejora el linfedema, sin embargo existen 2 teorías:

La primera, indica que la transferencia de nódulos ganglionares linfáticos vascularizados actúan como una "esponja" o "bomba", llevando la linfa hacia los nódulos, dirigiéndolo hacia la circulación venosa como ocurre normalmente a través de las confecciones linfovenosas en los tejidos trasplantados. Para confirmar esta hipótesis. Cheng et al. inyectaron indocianina directamente en el núcleo de la transferencia del nódulo ganglionar linfático vascularizado o en el colgajo. Bajo visión fluoroscópica en la vena donante y luego la vena receptora del grupo de transferencia nódulo ganglionar linfática, observaron la receptación y drenaje de linfa a través del grupo de transferencia de nódulo linfático vascularizado ${ }^{18}$.
La segunda teoría indica que la trasferencia de nódulo ganglionar linfático vascularizado mediante la linfangiogénesis o por estimulación de las confecciones linfáticas eferentes y aferentes entre el grupo transferido de nódulos ganglionares linfáticos vascularizados y la zona receptora comprometida, con la participación de mediadores linfangiogénicos que actúan localmente estimulando el crecimiento y la unión mediante anastomosis de los vasos linfáticos hacia la red linfática del grupo de transferencia de nódulo ganglionar linfático vascularizado. El principal mediador linfangiogénico es el Factor de Crecimiento Vascular Endotelial (VEGF), que ha mostrado promover éxito en la trasferencia de nódulo linfático vascularizado en animales.

Aunque no esté bien entendido el mecanismo de acción, la transferencia ganglionar de nódulo linfático vascularizado se ha convertido en el elemento principal de tratamiento del linfedema, con excelentes resultados demostrados por muchos autores. Se han descrito muchos grupos de transferencia de nódulo ganglionar vascularizado. Dentro de estos están: colgajo inguinal, colgajo submentoniano, colgajo supraclavicular, colgajo de omento y el colgajo torácico de nódulos linfáticos. Cada colgajo tiene sus ventajas y sus desventajas.

El colgajo inguinal es el más utilizado en la trasferencia de nódulos linfáticos vascularizados. Este colgajo está basado en los vasos de la ilíaca circunfleja superficial o la arteria medial de la arteria femoral común. Este colgajo presenta múltiples ventajas como ser: cicatriz imperceptible, anatomía confiable, presencia de múltiples nódulos linfáticos, y sobre todo la posibilidad de en conjunto con un colgajo abdominal para una reconstrucción mamaria total. Las desventajas de este colgajo serían: arteria donante de tamaño pequeño, pedículo vascular corto y la posibilidad de realizar un linfedema iatrogénico en caso extremo. Para evitar esta complicación se debe conocer el drenaje linfático abdominal y de la extremidad inferior. Generalmente el drenaje de los nódulos linfáticos de la extremidad inferior están localizados medirles a la arteria femoral, en el triangulo femoral; los nódulos linfáticos que drenan el abdomen se encuentran laterales y y mas superficial a la arteria femoral.

Los sitios receptores para la extremidad superior son: axila (vasos subescapulares), codo (vena basílica, arteria cubital recurrente) y muñeca (vena cefálica, venas subdérmicas, ramas dorsales de la arteria radial).

Los sitios receptores para la extremidad inferior son: ingle (vasos iliacos circunflejos superficiales), región posterior de la rodilla (vasos súbales medibles, vena safena magna, venas subdérmicas) y el tobillo (vasos tibiares posteriores, vasos pedios dorsales). 
Las zonas receptoras más utilizadas son la axila y la ingle, respectivamente, por ser zonas muy vascularizadas, los colgajos se mostraran más estéticos. En nuestra experiencia, la transferencia ganglionar vascularizada reduce la severidad del linfedema en la mayoría de las pacientes. La mejoría sintomática fue notoria. Disminuyendo por completo la incidencia de infeccion. En las dieciséis pacientes se demostró una disminución del perímetro del miembro afectado. Estos tratamientos quirúrgicos, si bien reducen la severidad del linfedema en la mayoría de las pacientes, no lo curan. Todas estas pacientes que fueron sometidas a esta cirugía, se les recomienda continuar con una terapia y tratamientos conservadores, incluyendo principalmente una terapia descongestiva compresiva mediante el uso de fajas compresivas, ejercicios terapéuticos, masajes drenantes. manuales.

Para un tratamiento adecuado de linfedema es necesario conocer y entender el diagnóstico y el grado de enfermedad, ya que es importante a la hora de proponer un tratamiento. La historia clínica con una correcta anamnesis y examen físico, son primordiales para un buen diagnóstico.

El gold standard para la evaluación del estado funcional del sistema linfático es la linfoscintigrafía. Esta utiliza una molécula unida al tecnecio $99 \mathrm{~m}$, que es inyectada en la dermis de la mano. Las imágenes subsecuentes revelarán el flujo dinámico, las áreas obs- truidas y/o el contraflujo dérmico, que nos darán una adecuada orientación de cómo tratar a la paciente.

Masià J et al., proponen un algoritmo a la hora de plantear una terapéutica. Considera que el punto esencial en el éxito del tratamiento es la selección correcta del paciente. Coinicidimos, ya que para poder realizar un tratamiento mediante un procedimiento fisiológico es necesario tener un sistema linfático funcionante para el éxito de la cirugía. Por lo que la parte más importante del proceso es la evaluación preoperatoria de la paciente. Propone un algoritmo llamado BLAST (Barcelona lymphedema algorithm for surgical treatment). Este no se basa en la clínica ni estadio del linfedema, sino en pruebas de imágenes preoperatorias.

\section{CONCLUSIÓN}

El linfedema secundario al tratamiento del cáncer de mama puede mejorar de forma exitosa y en un solo tiempo quirúrgico a través de la reconstrucción con colgajo DIEP y la transferencia de nódulo linfático vascularizado de la ingle a la axila, denominados estos colgajos en serie. Mediante este procedimiento, disminuye la progresión del linfedema a estadios más avanzados y mejora sustancialmente la calidad de vida la paciente. Los resultados son persistentes y favorables, aunque el seguimiento es aún escaso.

\section{BIBLIOGRAFÍA}

1. Becker C, Assouad J, Riquet M, et al. Postmastec-tomy lymphedema: long-term results following micro-surgical lymph node transplantation. Ann Surg 2006; 243(3):313-5.

2. Saaristo AM, Niemi TS, Viitanen TP, et al. Microvas- cular breast reconstruction and lymph node transfer for post mastectomy lymphedema patients. Ann Surg 2012;255(3):468-73.

3. Lee BB, Bergan J, Stanley RocksonByung-Boong Lee, et al, editors. Lymphedema. A concise compendium of theory and practice. 1st edition. Springer; 2011.

4. Becker C, Hidden G, Pecking A. Transplantation of lymph nodes: an alternative method for treatment of lymphoedema. Progr Lymphol 1990;4:487-93.

5. Becker C. Les transferts lymphatiques. Ann Chir Plast Esthet 2000.

6. Becker C. Actual treatment of lymphedema. e-Mem Acad Chir 2008;4(1):55-64.

7. Koshima I, Kawada S, Moriguchi T, Kajiwara Y. Ultrastructural observation of lymphatic vessels in lymphedema in human extremities. Plast Reconstr Surg 1996;97:397-405

8. . Cambria RA, Gloviczki P, Naessens JM, et al. Noninvasive evaluation of the lymphatic system with lymphoscintigraphy: a prospective, semiquantitative analysis in 386 extremities. J Vasc Surg. 1993; 18:773-782.

9. Mondry TE, Riffenburgh RH, Johnstone PA. Prospective trial of complete decongestive therapy for upper extrem-ity lymphedema after breast cancer therapy. Cancer J. 2004;10:42-48; discussion 17-19.

10. Dayes IS, Whelan TJ, Julian JA, et al. Randomized trial of decongestive lymphatic therapy for the treatment of lymphedema in women with breast cancer. J Clin Oncol. 2013;31:3758-3763.
11. Koshimal,InagawaK,UrushibaraK,etal.Supermicrosurgical lymphaticovenular anastomosis for the treatment of lymph-edema in the upper extremities. J Reconstr Microsurg. 2000;16:437-442.

12. Chang DW, Suami H, Skoracki R. A prospective analy- sis of 100 consecutive lymphovenous bypass cases for treatment of extremity lymphedema. Plast Reconstr Surg. 2013;132:1305-1314.

13. Masià J, Pons G, Rodríguez-Bauzà E. Barcelona lymphedema algorithm for surgical treatment in breast cancer-related lymphedema. J Reconstr Microsurg. 2016;32:329-335.

14. Becker C, Hidden G. Transfer of free lymphatic flaps. Microsurgery and anatomical study. J Mal Vasc 1988;13(2):119-22. Available at: http://www. ncbi.nlm.nih.gov/pubmed/3397670.

15. . Becker C, Assouad J, Riquet M, et al. Postmastec- tomy lymphedema: long-term results following microsurgical lymph node transplantation. Ann Surg 2006;243(3):313-5. Available at: http://wwwncbi. nlm.nih.gov/pubmed/16495693

16. DiSipio T, Rye S, Newman B, Hayes S. Incidence of unilateral arm lymphoedema after breast cancer: a systematic review and meta-analysi s. Lancet Oncol 2013:14(6):500-515

17. Ji-Na Yoo et al, Youn-Soo Cheong, Yu-Sun Min, Sang-Woo Lee.Validaty oj Quantitative Lymphoscintigraphy as a Lymphedema Assessment Tool for Patients With Cancer. Arm Annals of Rehabilitation Medicine. April 29, 2015.

18. Cheng-Hung Lin, Rozina Ali, Shin-Chen. Vascularized Groin Lymph Node Tranfer Using the Wrist as a Recipient Site for Management of Postmastectomy Upper Extremity Lymphedema.. Plast. Reconstr. Surg. 123:1265,2009)

19. Tobbia, Semple. Experimental Assessment of Autologous Lymph 
Node Transplantation as Treatment of Postsurgucal Lymphedema. Plast. Reconstr. Surg 124:777, 2009)

20. Chang. Lymphaticovenular Bypass for Lymphedema Management in Brest Cancer Patients: A Prospective Study. Plast. Reconst. Surg. 126:752, 2010

21. Charles RH. Elephantiasis Scroti. In: Latham A, English TC, eds. A System of Treatment, Vol. III. London: Churchill Linving- stone; 1912:504-513

22. Thomson N. The surgical treatment of chronic lympoedema of the extremities. Surg Clin North Am. 1967:47:445-503

23. Tompson N. Buried dermal flap operation for chronic lymphedema of the extremities: Ten-Year survey of results in 79 cases, Plast Reconstr Surg, 1970:45:541-548.

24. 24.Sistrunk WE. Cotribution to plastic surgery: Removal of scars by stages; an open operation for extensive laseration of the anal sphincter; the Kondoleon operation fon elephantiasis. Ann Surg. 1927:85:185-193

25. O'Brien BM, Khazanchi RK, Kumar PA, Dvir E, Pederson WC. Lipo- suction in the treatment of lymphoedema; a preliminary report. $\mathrm{Br} J$ Plast Surg. 1989;42:530-533.

26. Brorson $H$, Svensson H. Liposuction combined with controlled compression therapy reduces arm lymphedema more effectively than controlled compression therapy alone. Plast Reconstr Surg. 1998:102:1058-1067.

27. Baumeister RG, Siuda S. Treatment of lymphedema by microsurgical lymphatic grafting: What is proved? Plast Reconstr Surg. 1990;85:64-74; discussion 75-76.

28. Campisi C. Use of autologous interposition vein graft in management of lymphedema: Preliminary experimental and clinical observations. Lymphology 1991;24:71-76.

29. Campisi C, Boccardo F. Lymphedema and microsurgery. Microsurgery 2002;22:74-80.

30. Laine JB, Howard JM. Experimental lymphatic-venous anastomosis. Surg Forum 1963;14:111-112.

31. Yamada Y. Studies on lymphatic venous anastomosis in lymphedema. Nagoya J Med Sci. 1969;32:1-21. 